\title{
AN EXPERIMENTAL INVESTIGATION OF HEAT TRANSFER BY LAMINAR NATURAL CONVECTION ON A UNIFORMLY HEATED VERTICAL FLAT PLATE
}

\author{
Asish Mitra ${ }^{1}$ \\ ${ }^{1}$ Associate Professor and HOD, Basic Science and Humanities Department College of Engineering \& Management, \\ Kolaghat, East Midnapur, India-721171
}

\begin{abstract}
An experimental investigation on natural convection heat transfer under steady state condition has been conducted with water on a vertical flat plate of uniform heat flux. The plate was an electrically heated (uniform heat flux) flat plate. Water (100\%) was used as fluid. The plate temperature excess, $(\Delta T)_{x}$ increases vertically upwards as $x^{0.2}$ and is proportional to $q_{s}{ }^{0.8}$. The value of the coefficient of the well-established heat transfer correlation has been evaluated and its value shows a good agreement with the theoretical predictions and published data. Experimental data have been correlated as under:
\end{abstract}

$$
N u=0.41\left(R a^{*}\right)^{0.199}
$$

Keywords: Heat Transfer; Natural Convection; Vertical Plate; Uniform Heat Flux; Water

\section{INTRODUCTION}

Literature survey [1-10] shows that natural convective heat transfer from a single vertical plate of uniform heat flux has received attention over the last few decades.

In the present investigation, experimental studies have been conducted on natural convective heat transfer under steady state condition from a vertical flat plate of uniform heat flux. The apparatus used in this study consists of an electrically heated (uniform heat flux) flat plate. To get a steady state condition a pair of water-cooled plates was used on both sides of the hot plate. Heat transfer coefficients have been evaluated under steady state natural convective condition using water $(100 \%)$. The variation of the plate temperature excess, $(\Delta \mathrm{T})_{\mathrm{x}}$ with $\mathrm{x}$ and $\mathrm{q}_{\mathrm{s}}$ has been analyzed.

\section{EXPERIMENTAL APPARATUS AND DATA REDUCTION}

\subsection{Experimental Apparatus}

The experimental set-up (Fig. 1) consisted of an open top polycarbonate chamber having dimensions $34 \mathrm{~cm} \times 28 \mathrm{~cm} \times$ $62.5 \mathrm{~cm}$ (length, width, height), for housing a hot plate and a pair of cold plates and for holding the liquid [11]. The hot plate, dimensions $20 \mathrm{~cm} \times 5 \mathrm{~cm} \times 35 \mathrm{~cm}$ (length, width, height), was a U-shaped rectangular box made up of a thin sheet (thickness $0.8 \mathrm{~mm}$ ) of stainless steel (SS), which acted as a resistance heater. Its lateral edges were enclosed with non-conducting plastic sheets and sealed to make the box watertight. The bottom surface of the heater was thermally insulated by fixing rubber sheet (thickness $4 \mathrm{~mm}$ ) with the help of M-seal (trade name). Top of the heater box was open. It was connected to 220 volts, $50 \mathrm{~Hz}$ AC (Alternating Current) supply via a voltage stabilizer, a variable output step down transformer, a single-phase low voltage high amperage special type of transformer (0-4 volt, $0-1500$ ampere). A pair of identical cold SS plates (dimensions 20 $\mathrm{cm} \times 2 \mathrm{~cm} \times 35 \mathrm{~cm}$ ) was used as coolers to get steady state condition. The cooler SS plates were rectangular boxes, which had horizontal baffles inside as shown in Fig. 2. To ensure that

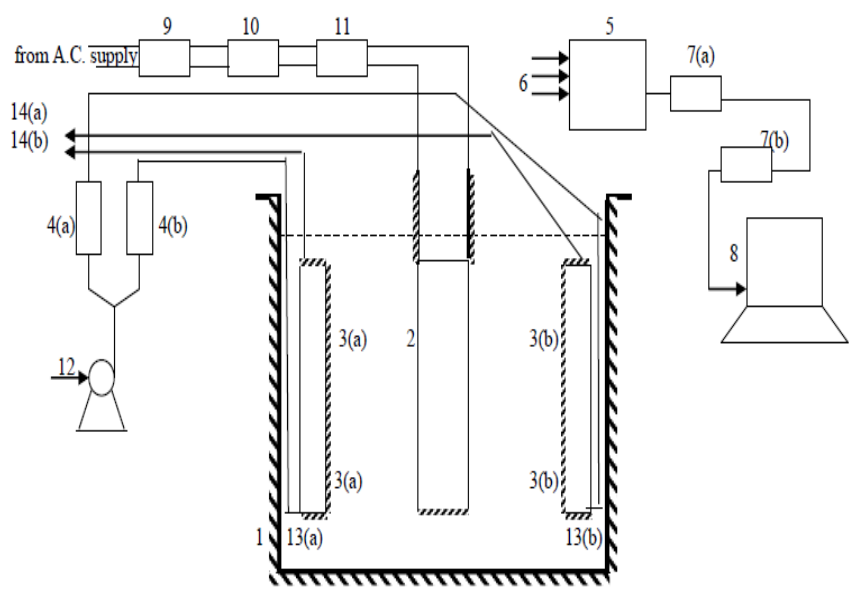

Fig. 1 The experimental set up (schematically):

1. Chamber, 2. hot plate, 3(a)-(b). water-cooled plates, 4(a)(b). water rotameters, 5. Hewlett Packerd Data Acquisition System, 6. inputs (voltage, current, temperatures), 7(a)-(b). line drivers, 8. PC, 9. voltage stabilizer, 10.variable output transformer, 11. low voltage, high amperage special transformer, 12. pump, 13. (a)-(b) coolant inlets, 14. (a)-(b) coolant outlets. 
heat transfer took place only through rear surfaces of the cold plates with respect to the hot plate, all other surfaces of the cold plates were thermally insulated by fixing rubber sheet (thickness $4 \mathrm{~mm}$ ) with the help of M-seal (trade name). Treated water at ambient temperature was used as the coolant, which entered each cooler plate at the bottom, and the same came out at the top. Flow rates of cooling water through the cold plates were monitored with the help of precalibrated rotameters. During experimental trials,

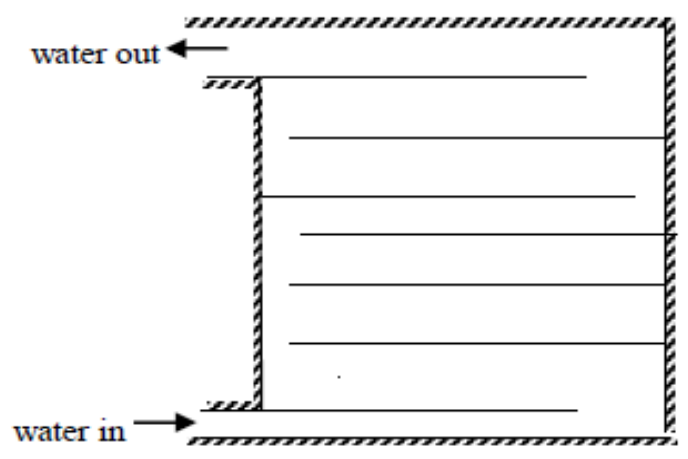

Fig. 2 Cold plate (sectional view)

cooling water flow rates were measured by collecting samples from time to time. Six K-type thermocouples were soldered on each surface of the hot and cold plates at different heights to measure the local surface temperatures. Six K-type thermocouples were also placed at different heights at the mid plane between the hot plate and the cold surfaces to record the cavity liquid temperature. Cooling water inlet and outlet temperatures were also measured with K-type thermocouples. The thermocouple terminals and heater energy input leads were connected to a HewlettPackard Data Acquisition System for scanning and logging the data into a PC through line drivers. The hot and cold plates were suspended in the polycarbonate chamber with a gap of $10 \mathrm{~cm}$ between the bottom surfaces of the plates and the chamber floor. The gap between the plates was $7.5 \mathrm{~cm}$. This distance did not affect the heat transfer. The bottom and the sides of the chamber were thermally insulated with glass wool pads. The gap between the hot and cold surfaces was adjusted to $10 \mathrm{~cm}$ so that the heated vertical plate was immersed as if in an infinite medium. The chamber was filled with water $(100 \%)$.

\subsection{Data Reduction}

Experimental data were logged after adjusting the power input and cooling water flow rate under transient and steady state conditions. To start with, the thermocouple readings went on increasing with time. Then they levelled off. The data obtained during this period were considered to be under steady state condition. During the entire period of a trial, cooling water rate and power input (voltage) were manually monitored. The set of discrete values of the different parameters and the range of variation of the thermo-physical properties of the fluid used in this investigation are listed in Tables 1 and 2 .
Table 1 Values of input parameters

\begin{tabular}{|l|l|}
\hline Heater heat flux, $\mathrm{KW} / \mathrm{m}^{2}$ & $5.81,8.57,12.86,15.71$ \\
\hline Cooling water rotameter reading, $1 / \mathrm{hr}$. & 60 \\
\hline
\end{tabular}

Table 2 Thermo-physical property variation range

\begin{tabular}{|l|l|l|}
\hline \multirow{2}{*}{$\begin{array}{l}\text { Temperature, }{ }^{\circ} \mathrm{C} \\
\text { Thermo-physical } \\
\text { properties }[11]\end{array}$} & Water \\
\cline { 2 - 3 } & $32^{\circ} \mathrm{C}$ & $44^{0} \mathrm{C}$ \\
\hline Density, $\rho, \mathrm{Kg} / \mathrm{m}^{3}$ & 995 & 991 \\
\hline Sp. heat, $\mathrm{C}_{\mathrm{p}}, \mathrm{J} / \mathrm{Kg} . \mathrm{K}$ & 4179 & 4180 \\
\hline Viscosity, $\mu, \mathrm{Kg} / \mathrm{m} \cdot \mathrm{s}$ & $7.647 \times 10^{-4}$ & $6.067 \times 10^{-4}$ \\
\hline Thermal Conductivity, $\mathrm{k}$, watt $/ \mathrm{mK}$ & 0.6217 & 0.6377 \\
\hline Volumetric thermal expansion coefficient, $\beta, \mathrm{K}^{-1}$ & $3.206 \times 10^{-4}$ & $4.152 \times 10^{-4}$ \\
\hline
\end{tabular}

The energy input rate to the heater which is the same as the heat transfer rate from the hot plate surface was taken as: $Q$ $=\mathrm{V} \times \mathrm{I}$, where, $\mathrm{V}$ is the voltage to the heater and $\mathrm{I}$ is the current through the heater. Under natural convective condition the liquid temperature, heater surface temperatures were observed to increase vertically upwards. When the system reached steady state, i.e., no variation of the thermocouple readings were observed over a period of time, the recorded data were used for calculation of $\mathrm{q}_{\mathrm{s}}, \Delta \mathrm{T}$ and $\mathrm{h}$. For calculating $\mathrm{h}$, the following relations were used:

$$
h=\frac{Q}{\Delta T \times A}=\frac{q_{s}}{\Delta T}
$$

where $\mathrm{h}$ is hot surface convective heat transfer coefficient, $\Delta \mathrm{T}$ temperature difference between bath and hot surface, $\left(\mathrm{T}_{\mathrm{h}, \mathrm{av}}-\mathrm{T}_{\mathrm{b}}\right.$, av $)$, A hot surface area. $\mathrm{T}_{\mathrm{h}, \mathrm{av}}$ and $\mathrm{T}_{\mathrm{b}}$, av were evaluated using the relation

$$
T_{a v}=\frac{\int_{0}^{L} T d L}{L}
$$

where $\mathrm{T}$ was expressed as a function of plate height $\mathrm{L}$ based on experimental data for each of $T_{h, a v}$ and $T_{b}$, av corresponding to each trial. The calculated values of natural convective heat transfer coefficient of the hot surface have been correlated in terms of Nusselt number $(\mathrm{Nu})$ and modified Rayleigh number $\left(\mathrm{Ra}^{*}\right)$. The thermo-physical properties of the fluid used in the different dimensionless groups were evaluated at the film temperature, $1 / 2\left(\mathrm{~T}_{\mathrm{h}, \mathrm{av}}+\mathrm{T}_{\mathrm{b}}\right.$, av).

\section{RESULTS AND INTERPRETATION}

As discussed earlier, experiments were performed at four different heat fluxes. Data obtained were correlated in the following form as proposed by some previous workers:

$N u=0.41\left(R a^{*}\right)^{0.199}, \quad r=0.99, \quad \sigma=0.257, \quad 5.91 \times 10^{12}<R a^{*}<2.61 \times 10^{13}$ 


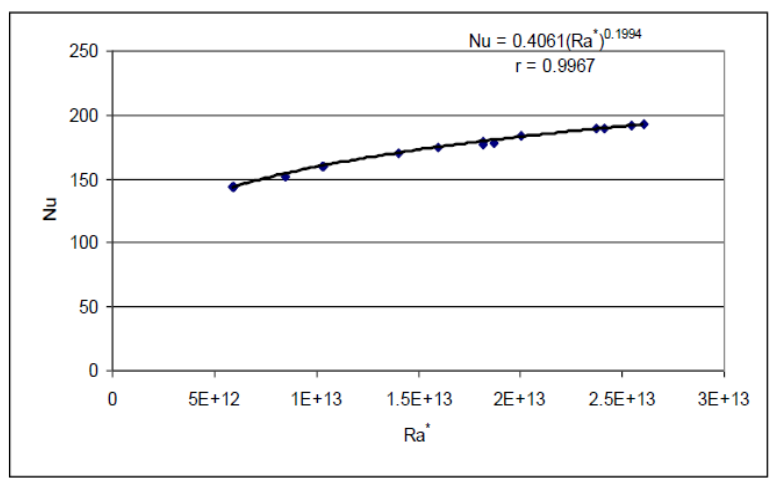

Fig. 3 Natural convective heat transfer correlation

Figure 3 shows the correlation graphically where correlation coefficient, $r=0.99$ and square-root of variance, $\sigma=0.257$. The correlation coefficient, $r$, [12] is a measure of the degree of association between $\mathrm{Ra}^{*}$ and $\mathrm{Nu}$. The above correlation agrees well with the standard formula $[1-3,7,10,11]$

$$
\mathrm{Nu}_{\mathrm{x}}=\mathrm{c}\left(\mathrm{Gr}^{*}{ }_{\mathrm{x}} \operatorname{Pr}\right)^{0.2}=\mathrm{cRa}_{\mathrm{x}}{ }^{* 0.2}
$$

The mean Nusselt number over the entire plate is then

$$
N u=\frac{5}{4} c\left(R a^{*}\right)^{0.2}=0.8 c\left(R a^{*}\right)^{0.2}
$$

Re-arranging equation (4)

$$
(\Delta T)_{x}=\frac{1}{c}\left[\frac{\mu}{g \beta \rho^{2} C_{p} k^{2}}\right]^{0.2} x^{0.2} q_{s}{ }^{0.8}
$$

Thus, a plot of $(\Delta \mathrm{T})_{\mathrm{x}}$ against $\mathrm{x}^{0.2}$ should be linear with $\mathrm{q}_{\mathrm{s}}$ as parameter, or a plot of $(\Delta \mathrm{T})_{\mathrm{x}}$ against $\mathrm{q}_{\mathrm{s}}^{0.8}$ should be linear with $\mathrm{x}$ as parameter if the physical properties of the fluid remain constant over the temperature range involved. The experimental data for $\mathrm{x}, \mathrm{q}_{\mathrm{s}}$ and $(\Delta \mathrm{T})_{\mathrm{x}}$ is listed in Table 3 .

Table 3 Variation of plate temperature excess $(\Delta T)_{x}$ with $x$ for different heat fluxes.

\begin{tabular}{|c|c|c|c|c|}
\hline \multirow{2}{*}{$\begin{array}{c}\text { Height from the } \\
\text { bottom edge, } \mathrm{x}, \mathrm{m}\end{array}$} & \multicolumn{4}{|c|}{ Plate temperature excess, $(\Delta \mathrm{T})_{\mathrm{x}}, \mathrm{K}$ for different heat flux, $\mathrm{q}_{\mathrm{s}}$, watt/ $\mathrm{m}^{2}$} \\
\hline & $\mathrm{q}_{\mathrm{s}}, 5810$ & $\mathrm{q}_{\mathrm{s}}, 8570$ & $\mathrm{q}_{\mathrm{s}}, 12860$ & $\mathrm{q}_{\mathrm{s}}, 15710$ \\
\hline 0.345 & 19.1 & 25.9 & 36.5 & 41.5 \\
\hline 0.30 & 18.2 & 25.4 & 34.9 & 41.1 \\
\hline 0.25 & 17.9 & 24.3 & 33.9 & 39.9 \\
\hline 0.20 & 17.4 & 22.8 & 32.5 & 37.8 \\
\hline 0.15 & 16.2 & 21.9 & 30.9 & 35.3 \\
\hline 0.10 & 14.5 & 20.4 & 28.4 & 33.2 \\
\hline 0.05 & 13.0 & 17.6 & 24.2 & 28.9 \\
\hline
\end{tabular}

The experimental points $\left[(\Delta \mathrm{T})_{\mathrm{x}} \mathrm{vs} . \mathrm{x}^{0.2}\right.$ with $\mathrm{q}_{\mathrm{s}}$ as parameter or $(\Delta \mathrm{T})_{\mathrm{x}}$ vs. $\mathrm{q}_{\mathrm{s}}{ }^{0.8}$ with $\mathrm{x}$ as parameter] are well represented by the straight lines passing through the origin (Fig $4 \mathrm{a}$ and $4 \mathrm{~b})$. The values of the parameter

$$
\mathrm{B}=(\Delta \mathrm{T})_{\mathrm{x}} / \mathrm{x}^{0.2} \mathrm{q}_{\mathrm{s}}^{0.8}
$$

for all cases were found to be constant as 0.023 [Table 4].
Table 4 Values of the parameter B for all cases.

\begin{tabular}{|c|c|c|c|c|}
\hline \multirow{2}{*}{$\begin{array}{c}\text { Height from the } \\
\text { bottom edge, } \mathrm{x}, \\
\mathrm{m}\end{array}$} & \multicolumn{4}{|c|}{$\mathrm{B}=(\Delta \mathrm{T})_{\mathrm{x}} / \mathrm{x}^{0.2} \mathrm{q}_{\mathrm{s}}^{0.8}$ for different heat flux, $\mathrm{q}_{\mathrm{s}}, \mathrm{KW} / \mathrm{m}^{2}$} \\
\cline { 2 - 5 } & $\mathrm{q}_{\mathrm{s}} 5.81$ & $\mathrm{q}_{\mathrm{s}} 8.57$ & $\mathrm{q}_{\mathrm{s}} 12.86$ & $\mathrm{q}_{\mathrm{s}, ~}, 15.71$ \\
\hline 0.345 & 0.023021 & 0.022874 & 0.023299 & 0.022571 \\
\hline 0.30 & 0.022558 & 0.023069 & 0.022909 & 0.022987 \\
\hline 0.25 & 0.023010 & 0.022889 & 0.023079 & 0.023144 \\
\hline 0.20 & 0.023388 & 0.022457 & 0.023136 & 0.022927 \\
\hline 0.15 & 0.023065 & 0.022848 & 0.023300 & 0.022679 \\
\hline 0.10 & 0.022389 & 0.023081 & 0.023223 & 0.023131 \\
\hline 0.05 & 0.023057 & 0.022874 & 0.022732 & 0.023129 \\
\hline
\end{tabular}

The plots in Figs $4 \mathrm{a}$ and $4 \mathrm{~b}$ are linear and the value of the parameter B turns out constant; so neglecting the effect of temperature on the physical properties of the fluid is justified. Considering the average values of the properties of water between the temperature range mentioned in Table 2, the value of the coefficient of the heat transfer relation (4) is then

$$
c=\left[\frac{\mu}{g \beta \rho^{2} C_{p} k^{3}}\right]^{0.2} / B=0.478
$$

And the value of the coefficient of equation (3) is then 0.38 , which is substantiated by the correlation developed using the experimental data: $N u=0.41\left(R a^{*}\right)^{0.199}$, [Fig 3]. The deviation is minor and falls within the realm of experimental uncertainty in measurement.

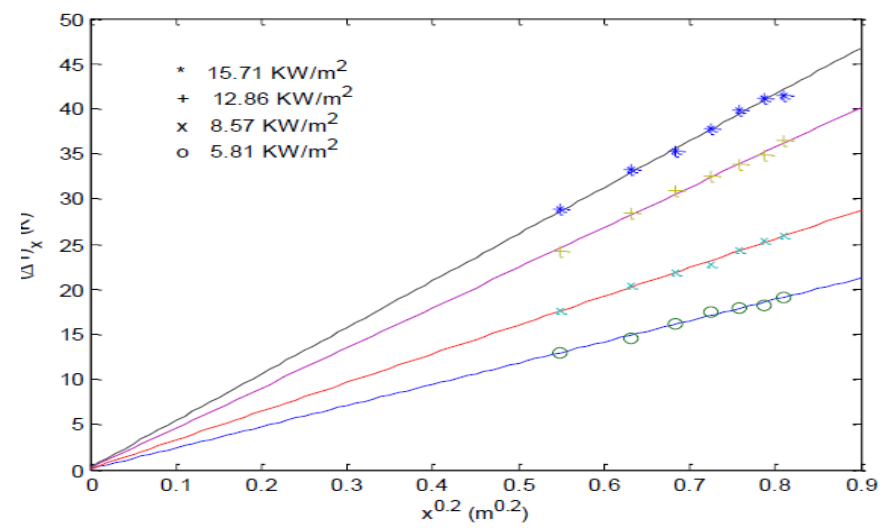

Fig 4a Experimental results: Variation of plate temperature excess, $(\Delta \mathrm{T})_{\mathrm{x}}$ with $\mathrm{x}^{0.2}$, heat flux, $\mathrm{q}_{\mathrm{s}}$ as parameter.

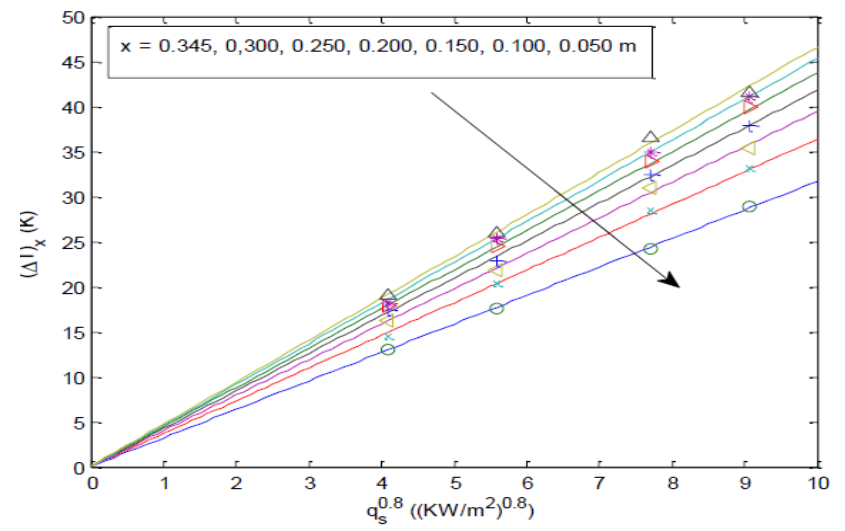

Fig 4b Experimental results: Variation of plate temperature excess, $(\Delta \mathrm{T})_{\mathrm{x}}$ with $\mathrm{q}_{\mathrm{s}}{ }^{0.8}, \mathrm{x}$ as parameter. 


\section{CONCLUSION}

Heat transfer studies from a vertical plate of uniform heat flux were experimentally investigated using water (100\%) under steady state natural convective condition. The experimental results are analyzed by considering the variation of $(\Delta \mathrm{T})_{\mathrm{x}}$ against $\mathrm{x}^{0.2}$ with $\mathrm{q}_{\mathrm{s}}$ as parameter, and the variation of $(\Delta \mathrm{T})_{\mathrm{x}}$ against $\mathrm{q}_{\mathrm{s}}{ }^{0.8}$ with $\mathrm{x}$ as parameter. The resulting linear relationships confirm the theoretical predictions, based on boundary layer theory. The near constancy of the parameter $\mathrm{B}=(\Delta \mathrm{T})_{\mathrm{x}} / \mathrm{x}^{0.2} \mathrm{q}_{\mathrm{s}}^{0} 8$ in all cases confirms the predicted dependence on heat flux. Finally, natural convection data from a single vertical plate of uniform heat flux have been correlated as:

$$
N u=0.41\left(R a^{*}\right)^{0.199}
$$

\section{REFERENCES}

[1] E. M. Sparrow, J. L. Gregg, Laminar free convection from a vertical plate with uniform surface heat flux, Trans. Am. Soc. Mech. Engrs 78 (1956) 435-440.

[2] R. J. Goldstein, E. R. G. Eckert, The steady and transient free conv ection boundary layer on a uniformly heated vertical plate, Int J Heat Mass Tran 1 (1960) 208-218.

[3] B. H. Chang, R. G. Akins Jr., L. Burris, S. G. Bankoff, Free convection of a low Prandtl number fluid in contact with a uniformly heated vertical plate, AEC Research and development Report ANL-6835, Argonne National Laboratory, IL, 1964.

[4] D. V. Julian, R. G. Akins, Experimental investigation of natural convection heat transfer to mercury, Ind. Eng. Chem. Fund. 8 (4) (1969) 641-646.

[5] W. W. Humphreys, J. R. Welty, natural convection with mercury in a uniformly heated vertical channel during unstable laminar and transitional flow, AIChE J. 21 (2) (1975) 268-274.

[6] R. G. Colwell, J. R. Welty, An experimental investigation of natural convection with low Prandtl number fluids in a vertical channel with uniform wall heat flux, J. Heat Trans. - T ASME 96 (1974) 448454.

[7] S. W. Churchill, H. Ozoe, A correlation for laminar free convection from a vertical plate, J. Heat Trans. T ASME 95 (4) (1973) 540-541.

[8] Tetsu Fujii, Motoo Fujii, The dependence of local Nusselt number on Prandtl number in the case of free convection along a vertical surface with uniform heat flux, Int J Heat Mass Tran 19 (1976) 121-122.

[9] Z. H. Qureshi and B. Gebhart, Transition and transport in a buoyancy driven flow in water adjacent to a vertical uniform flux surface, Int $\mathbf{J}$ Heat Mass Tran 21 (1978) 1467-1479.

[10] O. G. Martynenko, A. A. Berezovsky, Yu. A. Sokovishin, Laminar free convection from a vertical plate, Int J Heat Mass Tran 27 (1984) 869-881.

[11] A Mitra, T K Dutta, D N Ghosh, Natural convective heat transfer in water enclosed between pairs of differentially heated vertical plates, Heat Mass Transfer (2008) 45:187-192.
[12] R. H. Perry, D. Green, Perry's Chemical Engineers' Handbook, $6^{\text {th }}$ ed., McGraw-Hill, New York, 1985. 